\title{
Oronasal administration of lipopolysaccharide prepartum modulated plasma metabolite patterns in periparturient dairy cows
}

\author{
Summera Iqbal ${ }^{1}$, Qendrim Zebeli ${ }^{2}$, Dominik A. Mansmann ${ }^{1}$, Suzanna M. Dunn ${ }^{1}$, \\ Burim N. Ametaj ${ }^{1 *}$ \\ ${ }^{1}$ Department of Agricultural, Food and Nutritional Science, University of Alberta, Edmonton, Canada; \\ *Corresponding Author: burim.ametaj@ualberta.ca \\ ${ }^{2}$ Department for Farm Animals and Veterinary Public Health, Institute of Animal Nutrition and Functional Plant Compounds, Vienna, \\ Austria
}

Received 8 May 2013; revised 8 June 2013; accepted 18 June 2013

Copyright (C) 2013 Summera Iqbal et al. This is an open access article distributed under the Creative Commons Attribution License, which permits unrestricted use, distribution, and reproduction in any medium, provided the original work is properly cited.

\section{ABSTRACT}

The objective of this study was to evaluate whether repeated oronasal administration of LPS before parturition showed effects on metabolic and clinical responses in periparturient dairy cows. Hundred Holstein dairy cows were randomly allocated to two treatment groups $(n=50)$. Thirty cows out of 100 were randomly assigned for intensive sampling $(n=15)$ started at $28 d$ before the expected day of parturition. Cows received an oral and a nasal treatment of $2 \mathrm{~mL}$ and $1 \mathrm{~mL}$ of sterile saline solution $(0.15 \mathrm{M}$ of $\mathrm{NaCl}$, respectively, alone (control), or containing 3 increasing doses of LPS from Escherichia coli 0111:B4 as follows: 1) $0.01 \mu \mathrm{g} / \mathrm{kg}$ body weight (BW) on d $-28,2) 0.05 \mu \mathrm{g} / \mathrm{kg} \mathrm{BW}$ on $\mathrm{d}-25$, and -21 , and 3) $0.1 \mu \mathrm{g} / \mathrm{kg} \mathrm{BW}$ on $\mathrm{d}-18$ and -14 . Blood samples were collected from coccygeal vein at different time points around parturition and analyzed for glucose, lactate, non-esterified fatty acids (NEFA), cholesterol, and betahydroxybutyrate (BHBA). Clinical monitoring of animals was done throughout the experiment at different time points for overall health status, udder edema (UE), manure score, and body condition score (BCS). Results showed that oronasal administration of LPS increased concentrations of glucose and cholesterol in the serum compared to the control group $(P<0.05)$. The administration of LPS had no effect on concentrations of NEFA, BHBA, and lactate in the serum $(P>0.05)$. Oronasal LPS did not influence BCS, manure score or the incidence of UE $(P>0.05)$.
Overall, repeated oronasal administration of LPS modulated some serum metabolites related to energy metabolism around parturition in the treated cows. Further research is warranted to elucidate the mechanisms behind greater glucose and cholesterol status in the serum and their potential effects on long-term metabolic health status of dairy cows.

Keywords: Lipopolysaccharide; Oronasal; Dairy Cows

\section{INTRODUCTION}

Initiation of lactation in dairy cows is associated with a major dietary shift from a high forage low-grain diet before parturition to a diet consisting of highly degradable carbohydrates, to meet the energy demands for milk production. Frequently, these feeding practices are associated with development of sub-acute ruminal acidosis (SARA), leading to rumen dysbiosis [1,2], and the release of bacterial compounds with high immunogenic properties [3,4]. One of these compounds is endotoxin or lipopolysaccharide (LPS), a component of the outer leaflet of the external membrane of all Gram negative bacteria. Recently we demonstrated that feeding graded amounts of barley grain (i.e., $0 \%, 15 \%, 30 \%$, and $45 \%$ of the diet DM) resulted in a 6- to 14-fold increase in the concentration of endotoxin in the rumen fluid in cows fed $30 \%$ and $45 \%$ barley grain, respectively [5].

It has been suggested that ruminal endotoxin that breaks through the mucosal barriers [6], transfers into the portal vein or lymphatic system and is removed by macrophages located in the liver or other organs [7]. Ac- 
tivated macrophages initiate an overall immune response [7-9], that commonly is associated with perturbation of various plasma metabolites [9-11]. For example, our recent study demonstrated that oral administration of increasing doses of LPS, before and shortly after parturition, triggered changes in plasma metabolites with lowered concentrations of non-esterified fatty acids (NEFA), and $\beta$-hydroxy-butyrate (BHBA), but enhanced insulin and glucose in the plasma [12]. However, we observed that when cows were challenged with intermittent endotoxemia by infusing intravenously increasing doses of LPS, it decreased concentration of cholesterol, whereas increased BHBA and cortisol, however no effect was observed on glucose, NEFA, lactate, and insulin [13]. Earlier studies regarding intravenous administration of endotoxin indicated modulation in the concentrations of plasma NEFA and BHBA of heifers [14,15], and dairy cows [16].

The interest in mucosal immune stimulation and most importantly in using the mucosally induced tolerance as a form of immunomodulation to prevent against certain pathogens is increased recently. However, although our knowledge about a potential role of endotoxin in the etiopathogenesis of several periparturient diseases is increasing, there are only a limited number of investigations dealing with prevention of deleterious effects of translocated endotoxin on the host's health status. For example, pretreatment with LPS by the oral route was able to protect rats against sepsis through a regulation of anti-LPS antibody production [17]. Moreover, in-tramammary mucosal pretreatment of cows with LPS was shown to protect against experimental Escherichia coli mastitis [18]. In cows, oral administration of repeated doses of LPS, before and shortly after parturition, stimulated a humoral immune response against LPS [19]. Because dairy cows are exposed to large amounts of cellfree LPS, in particular in gastrointestinal mucosal tissues, especially during the postpartum period, it would be of interest to evaluate whether exposure of cows to LPS long before this critical period might support metabolic status of the cows. Therefore, we hypothesized that repeated oronasal exposure of periparturient dairy cows to LPS from E. coli 0111:B4 2 - 4 wk before parturition will affect their energy and lipid metabolism as well as overall health status. Therefore the objectives of this study were to evaluate metabolic and some clinical responses of dairy cows to repeated oronasal administration of LPS during the $28 \mathrm{~d}$ before and $28 \mathrm{~d}$ after the expected day of calving.

\section{MATERIALS AND METHODS}

\subsection{Cows, Diets, and Experimental Design}

The trial consisted of two groups of 50 Holstein cows each allocated into a longitudinal study. Out of this pool (i.e., 100 cows) two intensive sampling sub-groups were established. Thirty Holstein dairy cows at $28 \mathrm{~d}$ before the expected day of parturition were randomly allocated to two treatment groups $(\mathrm{n}=15)$ according to parity, milk production, disease susceptibility from previous year, and body condition scoring (BCS). Cows received an oral and a nasal treatment of $2 \mathrm{~mL}$ and $1 \mathrm{~mL}$ of sterile saline solution (control), respectively, or $2 \mathrm{~mL}$ oral and 1 $\mathrm{mL}$ nasal of sterile saline solution containing 3 increasing doses of LPS from E. coli 0111:B4 as follows: 1) $0.01 \mu \mathrm{g} / \mathrm{kg}$ body weight (BW) on $\mathrm{d}-28,2) 0.05 \mu \mathrm{g} / \mathrm{kg}$ BW on $\mathrm{d}-25$ and -21 , and 3) $0.1 \mu \mathrm{g} / \mathrm{kg} \mathrm{BW}$ on $\mathrm{d}-18$, and -14 . The lowest dose of $0.01 \mu \mathrm{g} / \mathrm{kg}$ of BW was chosen because previous experiments have shown minimal changes in metabolism of dairy cows at this concentration, whereas dose 3 was selected due to a maximum host response at this dose [14,16,20]. We recently established the effects of these doses on different immune parameters in dairy cows [19].

The crystalline $E$. coli LPS (Lipopolysaccharide-FITC from E. coli strain 0111:B4 supplied by Sigma-Aldrich Canada Ltd, Oakville, ON, Canada), containing $10 \mathrm{mg}$ of purified LPS was dissolved in $10 \mathrm{~mL}$ of doubly distilled water, as suggested by the manufacturer, and stored at $4^{\circ} \mathrm{C}$. For administration to the animals the daily dose was dissolved in $3 \mathrm{~mL}$ of sterile saline and then introduced into the oral and nasal cavity of the cows using sterile 5 $\mathrm{mL}$ disposable syringes (Becton, Dickinson and Company, BD, Franklin Lakes, NJ). Similarly, the same amount of carrier (i.e., $3 \mathrm{~mL}$ of sterile saline supplied by Sigma-Aldrich Canada Ltd, Oakville, ON, Canada) was sprayed oronasally to all cows in the CTR group.

Daily diet was offered as a total mixed ratio (TMR) and was formulated to meet or exceed the nutrient requirements of dry and early lactating cows as per NRC [21] guidelines. The close up diet fed to the dry cows was based on the $10 \%$ alfalfa hay, $63 \%$ barley silage and $27 \%$ diet supplement on the DM basis; whereas high ration fed to early lactating cows was based the on $10 \%$ alfalfa hay, $40.8 \%$ barley silage and $49.2 \%$ dairy supplement. Ingredients and chemical composition of the diets for the dry and early lactating cows are presented in Tables 1 and 2, respectively. All experimental procedures were approved by the University of Alberta Animal Care and Use Committee for Livestock and animals were cared for in accordance with the guidelines of the Canadian Council on Animal Care [22]. Veterinary supervision was provided to the animals throughout the experiment.

\subsection{Sampling Procedure}

Blood samples were collected at 7:00 from the tail 
Table 1. Ingredients and chemical composition of the diet for dry cows.

\begin{tabular}{ll}
\hline Ingredients, \% of DM & Prepartum diet \\
\hline Alfalfa hay & 10.0 \\
Barley silage & 63.0 \\
& \\
Alfalfa silage & 00.0 \\
CUD ${ }^{1}$ grain & 27.0 \\
Nutrient composition of cud grain (dietary supplement) \\
\% amount in 100 kg mix \\
Barley grain, rolled \\
Canola meal & 55.0 \\
Dairy dry cow micro-premix & 7.5 \\
Limestone & 6.2 \\
Animate & 8.7 \\
Molasses & 15.7 \\
Canola oil & 0.9 \\
Yeast & 4.1 \\
Cud & 1.7 \\
\hline
\end{tabular}

${ }^{1} \mathrm{CUD}=$ giving more mineral especially $\mathrm{Ca}$ to avoid milk fever in early lactating cows.

Table 2. Ingredients and chemical composition of the diet for early lactating cows.

\begin{tabular}{|c|c|}
\hline Ingredients, \% of DM & Early lactation diet \\
\hline Alfalfa hay & 10.0 \\
\hline Barley silage & 40.8 \\
\hline Dairy supplement & 49.2 \\
\hline \multicolumn{2}{|l|}{$\begin{array}{l}\text { Nutrient composition of dairy } \\
\text { supplement, } \% \text { amount in } 100 \mathrm{~kg} \text { mix }\end{array}$} \\
\hline ADE Vit Pak-30 Natural E & 0.056 \\
\hline Ruminant TM Pak & 0.1025 \\
\hline Selenium 1000 mg/kg (UNscr Fin Cr) & 0.065 \\
\hline Custom TM Complex pmx & 0.060 \\
\hline Di-calcium phosphate $21 \%$ & 1.25 \\
\hline Co-op alantic Corn Dist & 10.0 \\
\hline Corn ground & 25.0 \\
\hline Corn rolled & 30.105 \\
\hline Vit D-10,000 KIU/kg & 0.015 \\
\hline Diamond V XPC & 0.14 \\
\hline Magalac/Enertia & 1.00 \\
\hline Fermenten & 2.00 \\
\hline Limestone & 1.50 \\
\hline Mag Ox $-56 \%$ & 0.37 \\
\hline Canola meal & 15.5 \\
\hline Hi bypass soy (Amino plus) & 2.75 \\
\hline Soy bean meal $-47.5 \%$ & 6.50 \\
\hline Sodium bicarbonate & 1.00 \\
\hline Salt & 0.113 \\
\hline Pork-Tallow & 2.45 \\
\hline Biotin 2\%-Rovimix H-2 & 0.007 \\
\hline ADM Vit E 405 Vegetable source & 0.015 \\
\hline
\end{tabular}

vein using serum vacutaniers (Becton, Dickinson and Company, BD, Franklin Lakes, NJ) on the following sampling days; $-28,-25,-21,-14$, and -7 , before parturition and on $\mathrm{d}+7,+14,+21$, and +28 after parturition. Blood samples were left to coagulate, and then centrifuged (Rotanta 460R, Hettrich Zentrifugen, Tuttlingen, Germany) at $3000 \times \mathrm{g}$ and $4^{\circ} \mathrm{C}$ for $20 \mathrm{~min}$ to collect serum, which was stored at $-20^{\circ} \mathrm{C}$ until analyses.

\subsection{Clinical Monitoring of Animals}

Udder edema (UE) was estimated according to an evaluation scale of 1 - 3 with $1=$ healthy, 2 = partial edema, and $3=$ severe edema [23]. Evaluations were done on $d-14$ and -7 , before parturition, then on the day of calving, as well as on $\mathrm{d}+7$ and +14 after parturition.

Manure was evaluated and scored based on its consistency from scale 1 - 5 ( 1 = very liquid with consistency of pea soup, 2 = appeared runny, did not form a distinct pile; less than $2.5 \mathrm{~cm}$ in height and splattered when hitting the ground, 3 = optimal score, porridge-like appearance; stacked up at $4-5 \mathrm{~cm}$, had several concentric rings; plopping sound; sticked to shoe, $4=$ thicker; sticked to shoe; stacked up more than $5 \mathrm{~cm}, 5=$ firm fecal balls) [24]. Evaluations were done on $\mathrm{d}-14$, before parturition, and $+7,+14$, and +21 after parturition.

BCS was estimated by conformity of 3 trained individuals according to the evaluation system by Elanco Animal Health (a division of Eli Lilly and Company, Lilly Corporate Center, Indianapolis, IN). Estimations were undertaken on $\mathrm{d}-28$, and -14 , before parturition, then on the day of calving, as well as on $d+14$, and +28 after parturition.

Feed intake was recorded daily during the entire experimental period. All animals were at good health status when entering the experiment.

Disease and medication history was recorded for each cow throughout the entire experimental period. Data of disease incidences for different periparturient diseases including lameness, retained placenta, metritis, mastitis, milk fever, and left displaced abomasum (LDA) were collected for all dairy cows throughout the experimental period i.e., 28 days before and 28 days after parturition. Clinical monitoring for the disease incidence was conducted on each sampling day and every alternate day of the experimental period, and the person assessing clinical parameters was blinded (i.e., unaware) to the treatment groups.

\subsection{Serum Metabolites}

Concentrations of glucose in the serum were quantified by an enzymatic method with a kit provided by Diagnostic Chemicals Ltd. (Charlottetown, PE). The procedure involves phosphorylation and oxidation of glu- 
cose in samples resulting in the production of NADH, which produces a color proportional to the glucose concentration in the sample. All samples were tested in duplicate and serum glucose was then determined by reading on a microplate spectrophotometer (Spectramax 190, Molecular devices Corp., Sunnyvale, CA) at an optical density of $340 \mathrm{~nm}$. According to the manufacturer's instructions the lower detection limit of the test was 0.06 $\mathrm{mg} / \mathrm{dL}$.

Serum NEFA was quantitatively determined by an enzymatic colorimetric method using kits provided by Wako Chemicals (Richmond, VA). The principle of the test involves acylation of coenzyme A by a fatty acid in the sample in presence of acyl-CoA synthase and production of hydrogen peroxide in presence of acyl-CoA oxidase. Hydrogen peroxide, in presence of peroxidase, permits the oxidative condensation of 3-methyl-N-ethyl$\mathrm{N}$ - $\beta$-hydroxy ethyl-O-aniline with 4 -aminoantipyrine to form a purple colored adduct, which is proportional to the amount of NEFA in the sample. The test was modified as described by Johnson and Peters [25]. Duplicates were used to read serum contents at an optical density of $550 \mathrm{~nm}$, on a microplate spectrophotometer (Spectramax 190, Molecular devices Corp., Sunnyvale, CA). The measurable range of the kit was within $0.01-4.00$ $\mathrm{mEq} / \mathrm{L}$ NEFA.

Enzymatic measurement of BHBA by $\beta$-hydroxybutyrate dehydrogenase was used for measuring serum concentration of BHBA using a commercially available kit (Stanbio Laboratory, Boerne, TX). The principle of the test involves conversion of BHBA in the samples to acetoacetate and $\mathrm{NADH}$ at $\mathrm{pH} 8.5$ by $\beta$-hydroxybutyrate dehydrogenase in the presence of NAD. The NADH produced reacts with 2-p-iodo-phenyl-3-p-nitrophenyl-5phenyltetrazolium chloride (INT) in the presence of diaphorase to produce a color proportional to the concentration of BHBA in the sample. Controls and blanks were used in this procedure to eliminate the diffe rence in the color intensity. Serum BHBA was measured in duplicates by reading on a microplate spectrophotometer (Spectramax 190, Molecular devices Corp., Sunnyvale, CA) at an optical density of $505 \mathrm{~nm}$. The lower detection limit of the assay was $125 \mu \mathrm{moL} / \mathrm{L}$.

Concentrations of lactate in the serum were determined using commercially available lactate assay kits (Biomedical Research Service Center, Buffalo, NY). The principle of this test involves reduction of tetrazolium salt INT in a NADH-coupled enzymatic reaction of formazan, which exhibits a red color. The intensity of the red color is proportional to the concentration of lactate. The procedure was modified as described by Johnson and Peters [25]. The lactate standard provided in the kit was read at an optical density of $492 \mathrm{~nm}$ on a microplate spectrophotometer (Spectramax 190, Molecular devices Corp., Sunnyvale, CA).
Serum cholesterol was measured using kits provided by Diagnostic Chemicals Ltd. (Charlottetown, PE, Canada). The colorimetric method is based on the principle of hydrolyzing cholesterol esters to free cholesterol and oxidation of free cholesterol to cholest-4ene-3-one with simultaneous production of hydrogen peroxide. In the presence of peroxidase the hydrogen peroxide couples with 4-aminoantyine and p-hydroxybenzoate to yield a chromogen whose intensity is proportional to the concentration of cholesterol in the sample. Samples were prepared in duplicates and the reading of serum cholesterol was conducted with an optical density of $505 \mathrm{~nm}$ on a microplate spectrophotometer (Spectramax 190, Molecular devices Corp., Sunnyvale, CA).

\subsection{Statistical Analysis}

Data were analyzed using the MIXED procedure of SAS (SAS Institute Inc., Cary, NC, USA Version 9.1.3) as describe by the following model:

$$
Y i j l=\mu+\gamma i+\alpha j+\beta l+(\alpha \beta) j l+\varepsilon i j k l
$$

where Yijkl is the observation for dependant variables, $\mu$ is the population mean, $\gamma i$ is the independent parameter for animal $i, \alpha j$ is a population parameter corresponding to treatment $j, \beta l$ is the fixed effect of measurement time (relative to each LPS challenge) $l,(\alpha \beta) j l$ is the effect of treatment by time interaction, and $\varepsilon i j k l$ is the residual error. Degrees of freedom were approximated by the method of Kenward-Roger [26]. The measurements taken on the same cow but at different sampling hours and administration days were considered as double repeated measures in the model. The Kronecker product of a completely unrestricted variance-covariance matrix (for administration day) and a first-order autoregressive variance-covariance matrix (for time after LPS administration) was used to account for double repeated measures taken on individual cows across time [12]. Multiple differences between treatments were tested by the option SLICE. The significance limit was declared at $\mathrm{P}<0.05$, while a tendency was considered at $\mathrm{P} \leq 0.10$.

\section{RESULTS}

\subsection{Plasma Metabolites}

The oronasal LPS group had greater concentrations of glucose in the serum $(\mathrm{P}=0.03$; Figure 1). Furthermore, there was effect of measurement time $(P<0.01)$. At $d$ -14 before parturition concentrations of glucose started to decrease in both groups from 55 and $65 \mathrm{mg} / \mathrm{dL}$ to concentrations as low as 40 and $50 \mathrm{mg} / \mathrm{dL}$ for the control and the treatment groups, respectively. No interaction between the treatment and time was evidenced for both groups $(\mathrm{P}=0.33)$.

Although not quite reflected in the probability value, 


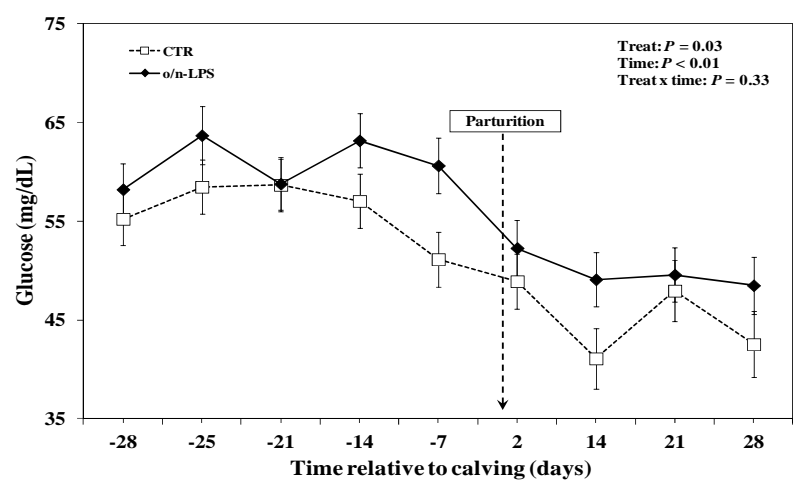

Figure 1. Concentration of glucose in the serum of periparturient Holstein dairy cows treated oronasally with increasing doses of lipopolysaccharide (o/n-LPS; $*$ ) or saline (Control: *). Treat $=$ Effect of treatment, Time $=$ Effect of sampling day, Treat $\times$ time $=$ Treatment by time interaction $(\mathrm{LSM} \pm \mathrm{SEM} ; \mathrm{n}=$ 15).

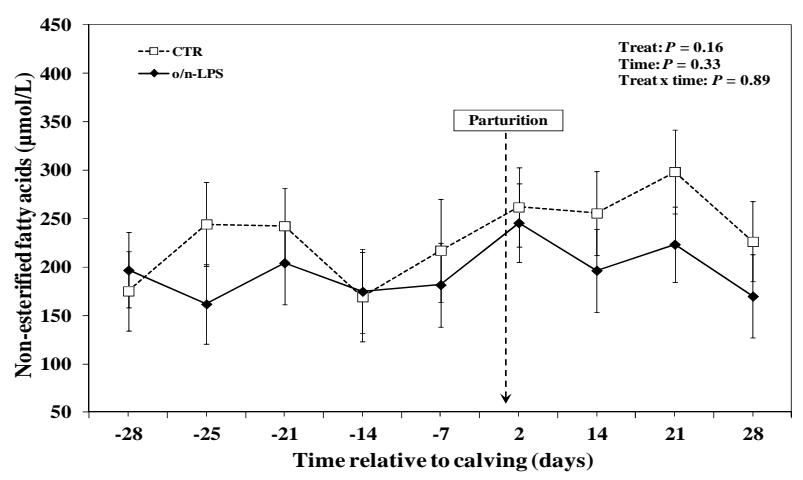

Figure 2. Concentration of non-esterified fatty acids in the serum of periparturient Holstein dairy cows treated oronasally with increasing doses of lipopolysaccharide (o/n-LPS; •) or saline $($ Control: $*)$. Treat $=$ Effect of treatment, Time $=$ Effect of sampling day, Treat $\times$ time $=$ Treatment by time interaction $(\mathrm{LSM} \pm \mathrm{SEM} ; \mathrm{n}=15)$.

concentrations of NEFA in treated cows were numerically below the control group values $(\mathrm{P}=0.16$; Figure 2$)$. There was no effect in the time or treatment by time interactions regarding NEFA $(\mathrm{P}=0.33 ; \mathrm{P}=0.89$, respectively). However, Figure 2 clearly shows two distinct peaks in the curve of NEFA for the control group, which does not occur at the same extent in the LPS-treated group. The first increase in serum NEFA is between $d$ -28 and -21 wk before calving and the second one at around $\mathrm{d}+14$ to +21 postpartum.

Concentrations of BHBA in the serum did not differ among treatments $(\mathrm{P}=0.95$; Figure 3$)$. The effect of measurement time was evident $(\mathrm{P}<0.01)$; however no interaction between treatment and time $(\mathrm{P}=0.66)$ was observed. Nevertheless, in the first $7 \mathrm{~d}$ postpartum concentration of BHBA in the serum of the LPS group remained lower compared to the control group. At around +21 and $+28 \mathrm{~d}$ postpartum concentrations of BHBA in- creased again in this group at an average concentration of $1200 \mu \mathrm{moL} / \mathrm{L}$.

The overall concentration of lactate in the serum was numerically higher in the LPS group during the treatment period and the first wk postpartum; although it did not reach the point of significance $(\mathrm{P}=0.11$; Figure 4$)$. Time had an effect on concentration of lactate, which was reflected in a decrease in the serum lactate in the control group $21 \mathrm{~d}$ before parturition, not observed in the LPS group. Along with parturition concentrations of lactate in the serum increased at a similar trend with the LPS group remaining higher within $3 \mathrm{~d}$ of calving $(\mathrm{P}<0.01)$. From a peak of 1200 and $1000 \mu \mathrm{moL} / \mathrm{L}$ for LPS and control groups, respectively, at 1 - 3 days postpartum concentrations of lactate in the serum decreased to $900 \mu \mathrm{mol} / \mathrm{L}$ for both groups of cows. However, there was no interaction between the treatment and time in this study $(\mathrm{P}=0.86)$.

Concentrations of cholesterol in the serum were greater in the LPS group ( $<0.01$; Figure 5). Time also had

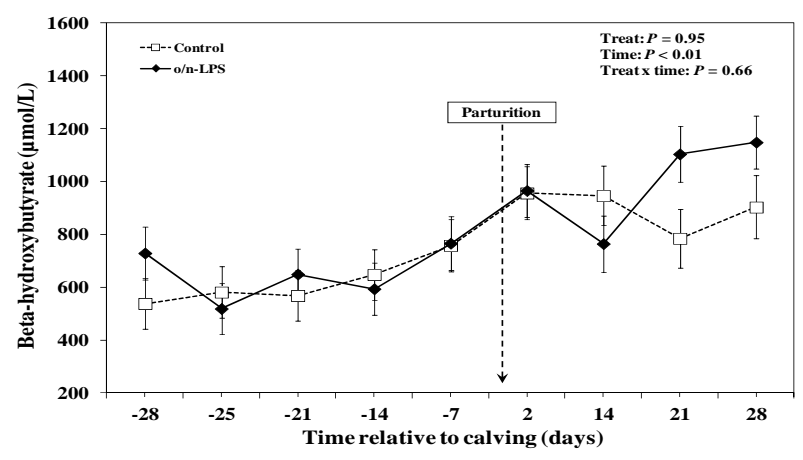

Figure 3. Concentration of beta-hydroxybutyrate in the serum of periparturient Holstein dairy cows treated oronasally with increasing doses of lipopolysaccharide (o/n-LPS; $\bullet$ ) or saline $($ Control: $*)$. Treat $=$ Effect of treatment, Time $=$ Effect of sampling day, Treat $\times$ time $=$ Treatment by time interaction $(\mathrm{LSM} \pm \mathrm{SEM} ; \mathrm{n}=15)$.

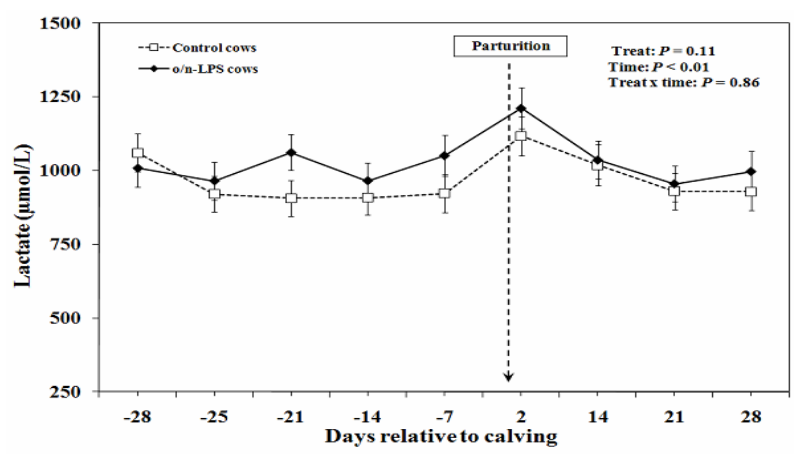

Figure 4. Concentration of lactate in the serum of periparturient Holstein dairy cows treated oronasal with increasing doses of lipopolysaccharide (o/n-LPS; $\bullet$ ) or saline (Control: *). Treat $=$ Effect of treatment, Time $=$ Effect of sampling day, Treat $\times$ time $=$ Treatment by time interaction $(\mathrm{LSM} \pm \mathrm{SEM} ; \mathrm{n}=$ $15)$. 
an effect on both groups with concentrations of cholesterol declining by $25 \%$ from $\mathrm{d}-28$ before calving to shortly after parturition and then recovering to original concentrations within a similar time $\operatorname{span}(\mathrm{P}<0.01)$. Both the LPS and the control curves followed a similar dynamic and no treatment by time interaction was observed $(\mathrm{P}=0.79)$.

\subsection{Clinical Parameters}

Body condition score was evaluated in 100 cows included in the trial. The overall effect of treatment was not significant $(\mathrm{P}>0.05$; Figure 6) regarding BCS. The factor measurement time around parturition showed considerable effect on weight loss in both groups $(\mathrm{P}<0.01)$. Furthermore, there was no treatment by time interaction for this variable $(\mathrm{P}>0.05)$. During transitioning period, from $\mathrm{d}-14$ before to $\mathrm{d}+14$ after parturition, both groups of cows followed a similar BCS loss trends.

Udder edema was also evaluated in groups of 100 cows. Treatment as a single factor had no effect on UE (P $>0.05$; Figure 7). However, time of measurement

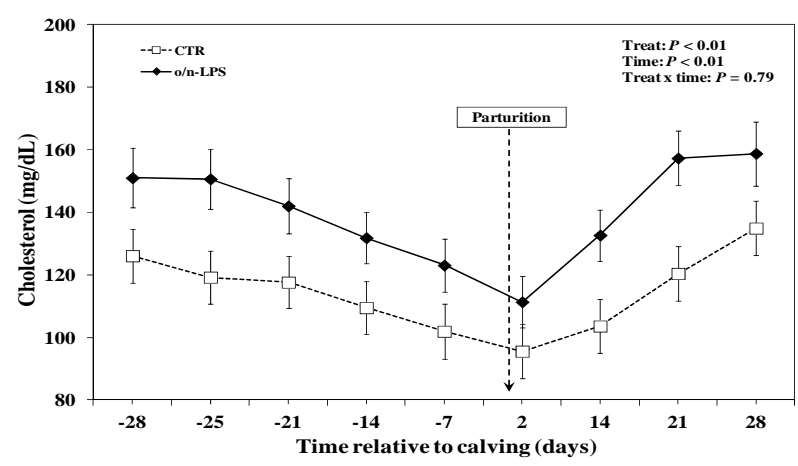

Figure 5. Concentration of cholesterol in the serum of periparturient Holstein dairy cows treated oronasal with increasing doses of lipopolysaccharide (o/n-LPS; $\bullet$ ) or saline (Control: *). Treat $=$ Effect of treatment, Time $=$ Effect of sampling day, Treat $\times$ time $=$ Treatment by time interaction $(\mathrm{LSM} \pm \mathrm{SEM} ; \mathrm{n}=$ 15).

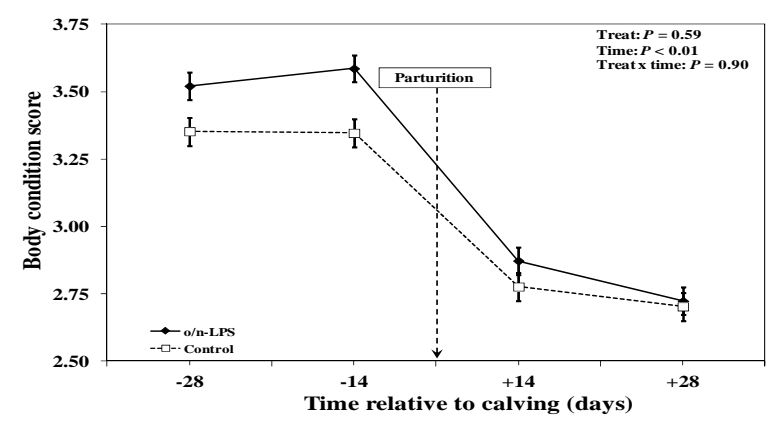

Figure 6. Body condition score (BCS) of periparturient Holstein dairy cows treated oronasal with increasing doses of $(\mathrm{o} / \mathrm{n}$-LPS; $\bullet$ ) or saline $($ Control: $*)$. Treat $=$ Effect of treatment, Time $=$ Effect of measurement day, Treat $\times$ time $=$ Treatment by time interaction $(\mathrm{LSM} \pm \mathrm{SEM} ; \mathrm{n}=50)$. showed an influence as indicated from variation in the prevalence of UE during different time points around parturition $(\mathrm{P}<0.01)$. Furthermore, interaction between treatment $\mathrm{x}$ time did not show an effect for this variable $(\mathrm{P}>0.05)$.

Data showed no effect of treatment on the manure score ( $\mathrm{P}=0.59$; Figure 8). Time around parturition affected the consistence of the manure, which was reflected in a lower average score after calving in treated cows $(\mathrm{P}<0.01)$. Furthermore, there was no treatment by time interaction for manure score between both treatment groups $(\mathrm{P}>0.05)$.

Data indicated that although oronasal administration of LPS did not show an influence on retained placenta and lameness $(\mathrm{P}>0.05)$, it was numerically lowered in the LPS cows versus the CRT group for both diseases. We observed 6 cases in the treated cows versus 13 cases in control group for retained placenta; whereas for lameness it was 9 cases in the oronasally-administered LPS cows versus 15 in the control group. Treatment showed a tendency for cows with more than one disease to be lower compared to cows in the control group $(\mathrm{P}=$

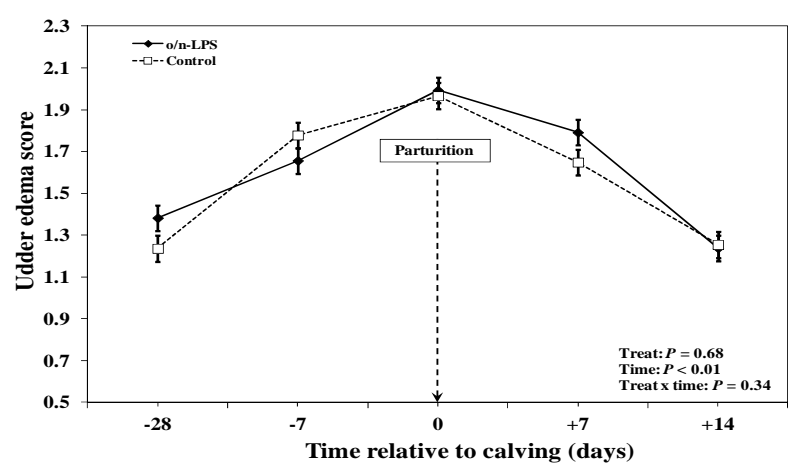

Figure 7. Udder edema (UE) scores of periparturient Holstein dairy cows treated oronasal with increasing doses of lipopolysaccharide (o/n-LPS; $\bullet)$ or saline $($ Control: $*)$. Treat $=$ Effect of treatment, Time $=$ Effect of measurement day, Treat $\times$ time $=$ Treatment by time interaction $(\mathrm{LSM} \pm \mathrm{SEM} ; \mathrm{n}=50)$.

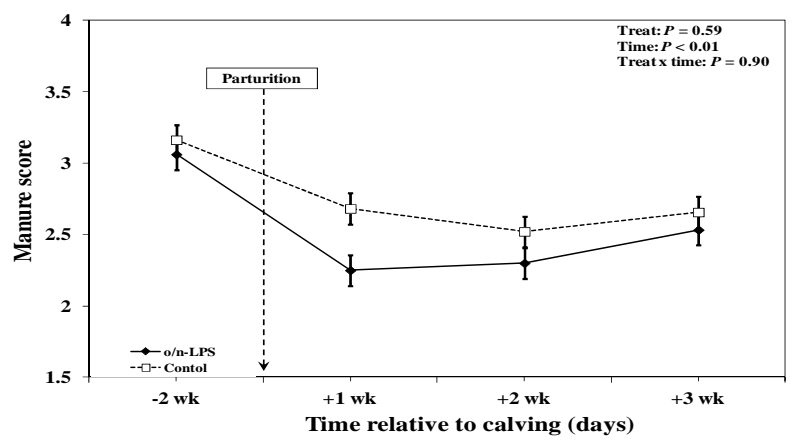

Figure 8. Manure score of periparturient Holstein dairy cows treated oronasally with increasing doses of lipopolysaccharide (o/n-LPS; $\bullet$ ) or saline (Control: *). Treat = Effect of treatment, Time $=$ Effect of measurement day, Treat $\times$ time $=$ Treatment by time interaction $(\mathrm{LSM} \pm \mathrm{SEM} ; \mathrm{n}=50)$. 
0.06). No effect on other clinical diseases was observed between the two treated groups (data not shown).

\section{DISCUSSION}

In a recent study we showed that repeated oral administration of LPS, $2 \mathrm{wk}$ before and $1 \mathrm{wk}$ after parturition, modulated several plasma metabolites and improved the innate immune status of dairy cows postpartum $[12,19]$. The present study aimed at evaluating whether repeated oronasal administration of LPS, for 3 consecutive wk, starting at $4 \mathrm{wk}$ before parturition, has the same effects on metabolic and clinical responses in periparturient dairy cows in a larger cohort of experimental animals. In the present trial, we split the doses of LPS into oral and nasal applications versus oral only application in our previous trial, and included 100 Holstein dairy cows in order to evaluate we decided to test this protocol is that dairy cows are exposed to large amounts of luminal cell-free LPS during the postpartum period. Therefore, we hypothesized that mucosal exposure of cows to LPS before this critical period (i.e., postpartum) might induce mucosal immunity against LPS and improve metabolic status of transition dairy cows. Several results of the energy metabolism obtained in the previous trial were confirmed in this experiment as well, some others were not, and all these are discussed below.

Results of the present study showed greater concentrations of serum glucose in the treatment group, which are in agreement with our previous research [12], and with other human and animal model studies [27,28]. Research in cows has shown that the response of plasma glucose to single endotoxin challenge is biphasic and associated with marked increase in peripheral glucose uptake $[29,30]$. It is interesting that serum glucose did not follow a biphasic pattern in this study, but it showed a continued higher response without interruption in the oronasal LPS-treated cows, which also confirmed our earlier findings where oral LPS administration around parturition induced a sustained greater blood glucose [12]. Although the exact mechanim(s) of how oronasal LPS causes greater blood glucose are not understood it is hypothesized that it might be either a stress response to repeated exposure to LPS or a better energy status of the cows as a result of increased immunity against LPS and prevention of its translocation into the host systemic circulation.

Another important finding of this study was greater serum cholesterol in cows administered oronasally with LPS. Recent research from our group showed that intermittent endotoxemia induced by infusing increasing doses of LPS via intravenous route is associated with decreased concentrations of cholesterol in the plasma of transition dairy cows [13]. This is in agreement with research in other species where LPS infusion subcutaneously for a period of $10 \mathrm{~d}$ showed a decrease in total plasma cholesterol and HDL cholesterol in cats [28], similar to humans experiencing endotoxemia $[31,32]$. It is known that cholesterol is a precursor of bile acids, which are engaged in detoxifying endotoxin [33], by splitting the toxic endotoxin moiety into nontoxic fragments and may lead to its neutralization by gastrointestinal proteins as well as prevent its translocation into the host blood circulation [34]. So greater serum cholesterol in the treated cows might indicate a better health status of those cows.

Data from this study showed that concentrations of lactate and NEFA in the serum were not different between the two treated groups. Although the LPS-treated cows had numerically greater lactate and lower serum NEFA the differences did not reach the point of significance. These data are not in accordance with our previous study where oral only administration of repeated and increasing doses of LPS in periparturient dairy cows increased lactate and lowered plasma NEFA [12]. The discrepancy might be related to different routes of administration of LPS (oral vs oronal) and splitting of the same dose into two different sites in the present study. It is a common finding in transition cows that low blood glucose is associated with greater serum NEFA $[9,35,36]$. It is known that chronic infusion of endotoxin induces the release of various inflammatory cytokines like tumour necrosis factor (TNF)- $\alpha$ which enhances lipolysis in subcutaneous fat tissue and the release of NEFA in blood circulation [37-39]. Waldron et al. [16] reported a biphasic response for plasma NEFA following iv infusion of endotoxin in dairy cows, with an initial decrease and a subsequent increase.

Data also showed that concentrations of BHBA in the serum remained unchanged between the treated groups. In addition, our data are different with those reported by Steiger et al. [15] and Waldron et al. [16], who demonstrated enhanced plasma BHBA in transition cows, and then a decrease following a single iv infusion of LPS. The difference of the present results with the latter studies is related to differences in the route of administration, dose of LPS used, and the time-length of administration. Of note, concentrations of BHBA in the serum were within the normal ranges in both treatment groups.

Treatment did not affect manure score, UE, and BCS. Previously we reported that the same dose of LPS administered orally improved health status of the treated cows [19]. The reason for the disagreement of results between the two studies might be related to the fact that the same dose of LPS was split between the nose and mouth in the present study. It is possible that splitting the dose of LPS might have lowered the required threshold 
dose to induce humoral immunity in experimental cows. Furthermore, oronasal application of LPS did not show beneficial effects on the incidence of clinical periparturient diseases of transition dairy cows. The reason for greater BCS in the treated cows, at some of the time points, is not clear at present and needs further investigation.

\section{CONCLUSION}

In conclusion, results of this study provided new evidence that oronasal administration of LPS was associated with enhanced concentrations of glucose and cholesterol. There was no effect of the treatment on serum NEFA, BHBA and lactate; although NEFA was numerically lowered and lactate was numerically greater in the treated cows. No effect was observed on manure score and UE. Treatment had no effect on the incidence rates of retained placenta, lameness, metritis, mastitis, milk fever, and LDA. Cows in the treatment group showed more optimal BCS during the transition period. This warrants further research regarding the optimal dose of LPS and the best routes of administration.

\section{ACKNOWLEDGEMENTS}

We acknowledge the financial support of Alberta Milk (Edmonton, Alberta, Canada), Alberta Livestock Industry Development Fund (Edmonton, Alberta, Canada), and Natural Sciences and Engineering Research Council of Canada (Ottawa, Ontario, Canada). We are grateful to the technical staff at Dairy Research and Technology Center, University of Alberta for their help and care of the cows.

\section{REFERENCES}

[1] Chou Zebeli, Q., Dijkstra, J., Tafaj, M., Steingass, H., Ametaj, B.N. and Drochner, W. (2008) Modeling the adequacy of dietary fiber in dairy cow based on responses of ruminal $\mathrm{pH}$ and milk fat production to composition of the diet. Journal of Dairy Science, 91, 2046-2066. doi:10.3168/jds.2007-0572

[2] Khafipour, E., Plaizier, J.C., Aikman, P.C. and Krause, D.O. (2011) Population structure of rumen Escherichia coli associated with subacute ruminal acidosis (SARA) in dairy cattle. Journal of Dairy Science, 94, 351-360. doi:10.3168/jds.2010-3435

[3] Ametaj, B.N., Zebeli, Q., Saleem, F., Psychogios, N., Lewis, M.J., Dunn, S.M., Xia, J. and Wishart, D.S. (2010) Metabolomics reveals unhealthy alterations in rumen metabolism with increased proportion of cereal grain in the diet of dairy cows. Metabolomics, 6, 583-594. doi:10.1007/s11306-010-0227-6

[4] Saleem, F., Ametaj, B.N., Bouatra, S., Mandal, R., Zebeli, Q., Dunn, S.M. and Wishart, D.S. (2012) A metabolomics approach to uncover the effects of grain diets on rumen health in dairy cows. Journal of Dairy Science, 95, 66066623. doi: $10.3168 / \mathrm{jds} .2012-5403$
[5] Emmanuel, D.G.V., Dunn, S.M. and Ametaj, B.N. (2008) Feeding high proportions of barley grain stimulates an inflammatory response in dairy cows. Journal of Dairy Science, 91, 606-614. doi:10.3168/jds.2007-0256

[6] Emmanuel, D.G.V., Madsen, K.L., Churchill, T.A., Dunn, S.M. and Ametaj, B.N. (2007) Acidosis and lipopolysaccharide from Escherichia coli 055:B5 cause hyperpermeability of rumen and colon tissues. Journal of Dairy Science, 90, 5552-5557.doi:10.3168/jds.2007-0257

[7] Ametaj, B.N., Zebeli, Q. and Iqbal, S. (2010b) Nutrition, microbiota, and endotoxin-related diseases in dairy cows. Revista Brasileira de Zootecnia, 39, 433-444.

[8] Andersen, P.H. (2003) Bovine endotoxicosis: Some aspects of relevance to production diseases. Acta Veterinaria Scandinavica, 8, 141-155. doi:10.1186/1751-0147-44-S1-S141

[9] Ametaj, B.N., Bradford, B.J., Bobe, G., Nafikov, R.A., Lu, Y., Young, J.W. and Beitz, D.C. (2005) Strong relationships between mediators of the acute phase response and fatty liver in dairy cows. Canadian Journal of Animal Science, 85, 165-175. doi:10.4141/A04-043

[10] Dougherty, R.W. (1976) Problems associated with feeding farm livestock under intensive systems. World Review of Nutrition and Dietetics, 25, 249-275.

[11] Nagaraja, T.G. and Lechtenberg, K.F. (2007) Acidosis in feedlot cattle. Veterinary Clinics of North America: Food Animal Practice, 23, 333-350. doi:10.1016/j.cvfa.2007.04.002,

[12] Zebeli, Q., Mansmann, D., Sivaraman, S., Dunn, S.M. and Ametaj, B.N. (2012) Oral challenge with increasing doses of LPS modulated the patterns of plasma metabolites and minerals in periparturient dairy cows. Innate Immunity, $1-17$.

[13] Zebeli, Q., Sivaraman, S., Dunn, S.M. and Ametaj, B.N. (2011) Intermittent parenteral administration of endotoxin triggers metabolic and immunological alterations typically associated with displaced abomasum and retained placenta in periparturient dairy cows. Journal of Dairy Science, 94, 4968-4983. doi:10.3168/jds.2011-4194

[14] Werling, D. (1996) Characterisation of the acute phase response of heifers to a prolonged low dose infusion of lipopolysaccharide. Research in Veterinary Science, 61, 252-257. doi:10.1016/S0034-5288(96)90073-9

[15] Steiger, M., Senn, M., Altreuther, G., Werling, D., Sutter, F., Kreuzer, M. and Langhans, W. (1999) Effect of a prolonged low-dose lipopolysaccharide infusion on feed intake and metabolism in heifers. Journal of Animal Science, 77, 2523-2532.

[16] Waldron, M.R., Nishida, T., Nonnecke, B.J. and Overton, T.R. (2003) Effect of lipopolysaccharide on indices of peripheral and hepatic metabolism in lactating cows. Journal of Dairy Science, 86, 3447-3459. doi:10.3168/jds.S0022-0302(03)73949-6

[17] Márquez-Velasco, R., Massó, F., Hernández-Pando, R., Montaño, L.F., Springall, R., Amezcua-Guerra, L.M. and Bojalil, R. (2007) LPS pretreatment by the oral route protects against sepsis induced by cecal ligation and puncture. Regulation of proinflammatory response and IgM 
anti-LPS antibody production as associated mechanisms. Inflammation Research, 56, 385-390. doi:10.1007/s00011-007-6116-4

[18] Petzl, W., Günther, J., Pfister, T., Sauter-Louis, C., Goetze, L., von Aulock, S., Hafner-Marx, A., Schuberth, H.J., Seyfert, H.M. and Zerbe, H. (2011) Lipopolysaccharide pretreatment of the udder protects against experimental Escherichia coli mastitis. Innate Immunity, 18, 467-477. doi:10.1177/1753425911422407

[19] Ametaj, B.N., Sivaraman, S., Dunn, S.M. and Zebeli, Q. (2012) Repeated oral administration of lipopolysaccharide from Escherichia coli 0111:B4 modulated humoral immune responses in periparturient dairy cows. Innate Immunity, 18, 638-647. doi:10.1177/1753425911434851

[20] Jacobsen, S., Toelboell, T. and Andersen, P.H. (2005) Dose dependency and individual variability in selected clinical, hematological and blood biochemical responses after systemic lipopolysaccharide challenge in cattle. Veterinary Research, 36, 167-178. doi:10.1051/vetres:2004062

[21] NRC (2001) Nutrient requirements of dairy cattle. 7th Edition, National Academies Press, Washington, DC, 381.

[22] Canadian Council on Animal Care (1993) Guide to the care and use of experimental animals. 2nd Edition, CCAC, Ottawa.

[23] Tucker, W.B., Adams, G.D., Lema, M., Aslam, M., Shin, I.S., Le Ruyet, P. and Weeks, L. (1992) Evaluation of a system for rating edema in dairy cattle. Journal of Dairy Science, 75, 2382-2387. doi:10.3168/jds.S0022-0302(92)77999-5

[24] Zaaijer, D., Kremer, W.D.J. and Noordhuizen J.P.T.M. (2005) Cow signals. Roodbont Publishers, Zutphen.

[25] Johnson, M.M. and Peters, J.P. (1993) A technical note: An improved method to quantify nonesterified fatty acids in bovine plasma. Journal of Animal Science, 71, 753756.

[26] Kenward, M. and Roger, J. (1997) Small sample inference for fixed effects from restricted maximum likelihood. Biometrics, 53, 983-997. doi:10.2307/2533558

[27] Bloesch, D., Keller, U., Spinas, G.A., Kury, D., Girard, J. and Stauffacher, W. (1993) Effects of endotoxin on leucine and glucose kinetics in man: Contribution of prostaglandin E2 assessed by a cyclooxygenase inhibitor. The Journal of Clinical Endocrinology and Metabolism, 77, 1156-1163. doi:10.1210/jc.77.5.1156

[28] Michaeli, B., Martinez, A., Revelly, J., Cayeux, M., Chioléro, R.L., Tappy, L. and Berger, M.M. (2012) Effects of endotoxin on lactate metabolism in humans. Critical Care, 16, R139. doi:10.1186/cc11444

[29] Onozaki, K. and Hashimoto, T. (1985) Different mechanisms of macrophage activation with guinea pig macrophage activation factor, lipopolysaccharide and muramyl dipeptide. International Archives of Allergy and Immu- nology, 76, 296-301. doi:10.1159/000233710

[30] Elsasser, T.H., Caperna, T.J., Li, C.J., Kahl, S. and Sartin, J.L. (2008) Critical control points in the impact of the proinflammatory immune response on growth and metabolism. Journal of Animal Science, 86, E105-E125. doi:10.2527/jas.2007-0634

[31] Fraunberger, P., Schaefer, S., Werdan, K., Walli, A.K. and Seidel, D. (1999) Reduction of circulating cholesterol and apolipoprotein levels during sepsis. Clinical Chemistry and Laboratory Medicine, 37, 357-362. doi:10.1515/CCLM.1999.059

[32] Khovidhunkit, W., Kim, M.S., Memon, R.A., Shigenaga, J.K., Moser, A.H., Feingold, K.R. and Grunfeld, C. (2004) Effects of infection and inflammation on lipid and lipoprotein metabolism: Mechanisms and consequences to the host. Journal of Lipid Research, 45, 1169-1196. doi:10.1194/jlr.R300019-JLR200

[33] Parlesak, A., Schaeckeler, S., Moser, L. and Bode, C. (2007) Conjugated primary bile salts reduce permeability of endotoxin through intestinal epithelial cells and synergize with phosphatidylcholine in suppression of inflamematory cytokine production. Critical Care Medicine, $\mathbf{3 5}$, 2367-2374. doi:10.1097/01.CCM.0000284586.84952.FB

[34] Bertok, L. (2004) Bile acids in physico-chemical host defence. Pathophysiology, 11, 139-145. doi:10.1016/j.pathophys.2004.09.002

[35] Duffield, T.F., Lissemore, K.D., McBride, B.W. and Leslie, K.E. (2009) Impact of hyperketonemia in early lactation dairy cows on health and production. Journal of Dairy Science, 92, 571-580. doi:10.3168/jds.2008-1507

[36] Hammon, H.M., Stürmer, G., Schneider, F., Tuchscherer, A., Blum, H., Engelhard, T., Genzel, A., Staufenbiel, R. and Kanitz, W. (2009) Performance and metabolic and endocrine changes with emphasis on glucose metabolism in high-yielding dairy cows with high and low fat content in liver after calving. Journal of Dairy Science, 92, 15541566. doi:10.3168/jds.2008-1634

[37] Gabay, C. and Kushner, I. (1999) Acute-phase proteins and other systemic responses to inflammation. New England Journal of Medicine, 340, 448-454. doi:10.1056/NEJM199902113400607

[38] Kushibiki, S., Hodate, K., Shingu, H., Obara, Y., Touno, E., Shinoda, M. and Yokomizo, Y. (2003) Metabolic and lactational responses during recombinant bovine tumor necrosis factor-alpha treatment in lactating cows. Journal of Dairy Science, 86, 819-827. doi:10.3168/jds.S0022-0302(03)73664-9

[39] Bradford, B.J., Mamedova, L.K., Minton, J.E., Drouillard, J.S. and Johnson, B.J. (2009) Daily injection of tumor necrosis factor-\{alpha\} increases hepatic triglycerides and alters transcript abundance of metabolic genes in lactating dairy cattle. Journal of Nutrition, 139, 1451-1456. doi:10.3945/jn.109.108233 